\title{
Salience and metaphysical explanation
}

\section{Phil Corkum $^{1} \mathbb{D}$}

Received: 25 August 2020 / Accepted: 14 June 2021

(ᄋ) The Author(s), under exclusive licence to Springer Nature B.V. 2021

\begin{abstract}
Metaphysical explanations, unlike many other kinds of explanation, are standardly thought to be insensitive to our epistemic situation and so are not evaluable by cognitive values such as salience. I consider a case study that challenges this view. Some properties are distributed over an extension. For example, the property of being polka-dotted red on white, when instantiated, is distributed over a surface. Similar properties have been put to work in a variety of explanatory tasks in recent metaphysics, including: providing an analysis of change, giving to presentists truthmakers for past claims; giving to priority monists an account of basic heterogeneous entities; and giving to friends of extended simples an explanation of how an extended simple can enjoy qualitative variation. I argue that such explanations exhibit salience failure. How ought we represent the semantics of salience? Differences in linguistic stress induce semantic differences similar to the semantic differences induced in explanations by differences in salience, and I will draw an analogy with linguistic theories of focus sensitivity to sketch how one might model the role of salience in these kinds of explanations. I end with a few tentative conclusions about the role of cognitive values in metaphysical explanations. Some theorists view the citation of a ground as a sufficient explanation. If certain explanations appealing to distributed properties exhibit attenuated salience, then arguably the mere citation of a ground does not always provide an adequate explanation.
\end{abstract}

Keywords Grounding · Cognitive values · Presentism · Extended simples · Priority monism $\cdot$ Focus sensitivity

Phil Corkum

phil.corkum@ualberta.ca

1 University of Alberta, Edmonton, Canada 


\section{Introduction}

'Explanation' is ambiguous between the reason something is so, and the act of conveying that reason. I will call the former a reason, and reserve explanation for the latter. ${ }^{1}$ The reason is a fact that obtains independently of our interests, purposes and background beliefs; independently of our representation of such facts; and independently of the cognitive limitations that must be overcome for us to appreciate that such a fact is indeed a reason why something is so. An explanation, by contrast, is a linguistic activity sensitive to the epistemic situation of its participants. The interests, purposes, shared beliefs, modes of representation, and cognitive limitations of the interlocutors all influence the success of an explanation.

For me to succeed in conveying to you a reason why something is so, I must consider our shared beliefs and intentions, and the currently available evidence. And I must take into consideration our limited abilities to recognize each other's beliefs and intentions, to present and assess the evidence, and to follow the reasoning that leads us from our background beliefs and the presented evidence to a new belief. And so an act of explanation is evaluable by a range of cognitive values. For example, ideological simplicity is a cognitive value since, all else being equal, explanations with fewer primitive concepts are easier to understand than explanations with more. Similar comments could be made for such values as ontological parsimony, consistency with accepted beliefs, fecundity, predictive power, and salience.

Explanations come in a variety of kinds: causal explanations convey causal facts; epistemic explanations convey reasons to believe that something is the case, and so on. This is a paper about metaphysical explanations. To repeat a well worn example, in the Euthyphro Plato floats the claim that an act is loveable to the gods in virtue of its being pious. The relation between an act being pious and its being loveable to the gods is explanatory but it's not one of a variety of common kinds of explanations. For example, the relation is neither causal nor a generalization: being pious neither causes, nor merely typically correlates with, being loveable to the gods. If metaphysical explanations have the same structure as other explanations, then they convey facts about what grounds what - that is to say, facts about the relatively fundamental, and about how these fundamental facts determine facts about derivative entities-and this conveyance is evaluable by the range of cognitive values discussed above. The role of cognitive values in metaphysical explanations is an understudied topic. Indeed, it would be controversial to claim that metaphysical explanations are evaluable by cognitive values at all.

Some grounding theorists draw a distinction between grounds and metaphysical explanations. For example, Paul Audi (2012, pp. 687-688) argues for the existence of grounding relations on the basis of an analogy with the reason-explanation structure of causal explanations: "if we recognize [cases of non-causal explanation] and we agree that explanations require non-explanatory relations underlying their

\footnotetext{
1 Some theorists make a similar distinction between the explanation and the backing relation underwriting that explanation. For example, Ruben (1990) draws this distinction in discussion of causal and scientific explanations. Skow (2016) makes a similar distinction between the reason why and the explanation.
} 
correctness, then we are committed to recognizing a non-causal relation at work in these explanations." ${ }^{2}$ Such an approach would allow for objective worldly facts to back explanations, while the explanations themselves might be sensitive to cognitive considerations.

Other grounding theorists, by contrast, view grounding as itself an explanatory relation. For example Kit Fine (2001, p. 15) writes: "We take ground to be an explanatory relation: if the truth that $P$ is grounded in other truths, then they account for its truth; $P$ 's being the case holds in virtue of the other truths' being the case."3 Raven (2015) helpfully labels those who distinguish metaphysical explanations from the worldly facts which back such explanations separatists, and those who take grounding to be an explanatory relation unionists. The appearance of disagreement between separatists and unionists may arise only from the ambiguity of "explanation' and similar terminology. But if there is substantive disagreement, it may hinge on the nature of the explanation provided by the citation of a ground. Raven (2015, p. 326) characterizes this disagreement:

unionists might be inspired by ... [an] analogy with cause and causal explanation (cf. Strevens [2008]). Just as some kind of worldly explanation is given merely by citing what causes what, unionists might also say that so too some kind of worldly explanation is given merely by citing what grounds what. Unionists might then concede that this kind of explanation of ground needn't satisfy just any of the explanatory interests or goals active in a given context without thereby undermining the legitimacy of the kind of explanation it does provide. If so, perhaps the burden is on the separatist to explain why ground itself provides not even this kind of explanation (whatever it is).

On this interpretation of unionism, the kind of explanation provided by grounding facts is independent of our epistemic situation. The grounding fact obtains, and so determines the grounded fact. That this is so, unionists might well hold, is sufficient for some kind of explanation of the grounded fact. The mere citation of a fact is relatively insensitive to the interlocutors' epistemic situation. Citation incurs the requirements of any assertion. Information will not be conveyed unless, for example, known terminology is used. But provided these minimal prerequisites are met, citation is arguably not further evaluable by cognitive values such as salience and parsimony.

Raven poses a challenge to those like myself who would view metaphysical explanations as cognitively evaluable. In this paper I will consider, as a case study, a class of metaphysical explanations that arguably exhibit salience failure, and so attempt to meet this challenge.

A map of the paper may be helpful to the reader. I will begin by introducing our case study. Some properties are distributed over an extension. For example, the

\footnotetext{
2 Others who make a similar distinction include Correia and Schnieder (2012), Koslicki (2012), Schaffer (2012) and Trogdon (2013). I do not claim that any of these authors view metaphysical explanations as cognitively evaluable, only that their approach allows the question of cognitive evaluation to be raised.

3 Others with similar views include Rosen (2010), Raven (2012), Dasgupta (2014) and Litland (2013).
} 
property of being polka-dotted red on white, when instantiated, is distributed over a surface. Similar properties have been put to work in a variety of explanatory tasks in recent metaphysics, including: providing an analysis of change, giving to presentists truthmakers for past claims; giving to priority monists an account of basic heterogeneous entities; and giving to friends of extended simples an explanation of how an extended simple can enjoy qualitative variation. In these contexts, then, facts about properties that are distributed over an extension are cited to ground local features (§2). These explanations have met with criticism, and I will argue that the objections in the literature miss their target $(\S 3)$. Rather, I will propose that these explanations exhibit salience failure. In brief, I will present salience as a psychological state, possessed by the interlocutors within a discourse, involving a certain kind of attention to a feature or state of affairs (this characterization will be unpacked in due course). Generally, explanations that draw on salient features of the reason why something is the case are, all else being equal, easier to follow, assess and appreciate, than those that do not. An explanation is more likely to succeed in conveying to the intended audience the reasons why something is the case, if it appeals to those very features of that reason to which the audience is attending. I will argue that certain metaphysical explanations that cite grounds exhibit attenuated salience $(\S 4)$. How ought we represent the semantics of salience? Differences in linguistic stress induce semantic differences relevantly similar to the semantic differences induced in explanations by differences in salience, and I will draw an analogy with linguistic theories of focus sensitivity to sketch how one might model the role of salience in these kinds of explanations (\$5). Finally, I will draw a few conclusions about the role of cognitive values in metaphysical explanations (§6). If certain explanations appealing to distributed properties exhibit attenuated salience, then arguably the mere citation of a ground does not always provide an adequate explanation, and so unionism is false. (I will also consider how an unionist might respond.)

\section{Distributionalism}

Some properties are distributed over an extension. For example, the property of being polka-dotted red on white, when instantiated, is distributed over a spatial extension. Introduced by Parsons (2000, 2004), such properties can be distributed over an extension in a variety of ways. For example, being red all over is a property which, when instantiated, is uniformly distributed over a surface. Being polka-dotted red on white is a colour property which, when instantiated, is non-uniformly distributed over a surface. And it seems that other properties can be distributed over times. Cameron (2011, p. 63) gives an example.

Consider a simple world consisting of just one spatial dimension and one temporal dimension. There is one entity in this world-Flatty-who starts off his life at time $\mathrm{t}$ as a point, but who as time progresses grows continuously in one direction of the one spatial dimension he occupies. After the beginning of this life, then, he is no longer a point but a line; and at each moment he is a longer 
line than he has ever been previously. Exactly one year later, at $t^{*}$, Flatty tragically ceases to be, and the world is empty.

Flatty's life might be described as instantiating a property distributed over time, from point to line segment. It will be useful to distinguish the underlying distributional property from its point features. Flatty has various lengths at different moments of his life. Each length is a point feature. Yet Flatty has one and the same distributional property at each moment of his life. To give another example, one might view my growing up as the distributional property of being initially a child and then an adult. Under commonly held endurantist assumptions, I had the point feature of being a child and now have the point feature of being an adult. But according to the proposal at hand, I have now one and the same distributional property as I had then, a property of maturation distributed over time.

Many non-uniform distributional properties are equivalent to a set or arrangement of non-distributional or uniform distributional properties. Consider being polka-dotted red on white. Parts of the surface are red and other parts, white. The surface is polka-dotted but, it may well seem, not in virtue of having some property over and above being red and white in a certain way. For one might think of the parts of the surface that are wholly red as having the uniform distributional property of being red all over and the parts of the surface that are wholly white as having the uniform distributional property of being white all over. Indeed, when we go down to point-sized parts of the surface, we reach non-distributional properties of being red and being white. So the property of being polka-dotted red on white appears to be equivalent to the non-distributional properties of being red and being white, along with a certain arrangement or spatial relationship.

Parsons (2004) however argues that at least some non-uniform distributional properties are irreducible - that is to say, some are not necessarily co-extensive with non-distributional or uniform distributional properties. The argument hinges on the extension, over which the property is distributed, being possibly gunky. Any part of gunk has itself proper parts. So gunk is divisible all the way down: gunk is not composed of mereological atoms. For the classic discussion of gunk, see Lewis (1991). Many of the details of Parsons' argument will not concern us, ${ }^{4}$ but I will next note that the employment of distributional properties within certain metaphysical explanations requires that the relevant property is irreducible.

Distributional properties have been put to work in a variety of explanatory tasks in recent metaphysics, including: responding to the truthmaker objection to presentism ${ }^{5}$; providing an analysis of change ${ }^{6}$; giving to priority monists an account of basic heterogeneous entities ${ }^{7}$; giving to existence monists an explanation how the

\footnotetext{
${ }^{4}$ I discuss Parson's argument only briefly-in part because the issue is peripheral to the salience objection, in part because one can simply stipulate that the distributional property is irreducible, and in part since I discuss the argument at length in Corkum (2014).

${ }^{5}$ Cameron (2008, 2011, 2013); discussed in Caplan and Sanson (2011), Tallant and Ingram (2012a, b, 2015), Cameron (2013), Effingham (2013), Davidson (2013), Corkum (2014), Green (2017).

${ }^{6}$ Parsons $(2000,2004)$, Cameron $(2008,2011)$.

${ }^{7}$ Cornell $(2013,2016)$.
} 
world, although mereologically simple, is heterogeneous ${ }^{8}$; and giving to friends of extended simples an explanation how an extended simple can enjoy qualitative variation. ${ }^{9}$ Let's look in just a little more detail at a few examples where irreducible nonuniformly distributed properties are put to philosophical use.

Our first example. Parsons (2004, pp. 178-180) and Cameron (2011, p. 77) propose an analysis of change in terms of properties non-uniformly distributed over time. Parsons (2004) proposes the following account of change: "an object changes iff it has a non-uniform temporal distributional property. More specifically, an object changes in a respect $\varphi$ (where $\varphi$ might be "heat", or "mass", or "believing in the Hegelian Dialectic") iff it has a non-uniform temporal $\varphi$-distribution." Cameron's proposal occurs within his argument that a presentist may appeal to temporally distributed properties so to serve as truthmakers for past claims. Cameron considers an objection to his view, namely that distributional properties would themselves change. Cameron (2011, p. 77) responds to the objection in the following way.

It makes no sense to speak of an object changing its distributional properties. Why? Because what change is on the account being offered is to instantiate (at each moment of your existence) a nonuniform distributional property. Being red at one time and then orange at some later time, for example, is to be analysed as instantiating (at all times) the distributional property being red-thenorange. To speak of an object changing its properties is a loose way of saying something about the distributional property it has that says how it is across time; it makes no sense to speak of an object gaining or losing the property that says how it is across time.

Distributional properties offer a novel analysis of change. According to this account, an object $\mathbf{x}$ changes just in case there is a property $\mathbf{p}$ and times $\mathbf{t}_{\mathbf{1}}<\mathbf{t}_{\mathbf{2}}$ such that $\mathbf{x}$ is $\mathbf{p}$ at $\mathbf{t}_{\mathbf{1}}, \mathbf{x}$ is $\mathbf{p}$ at $\mathbf{t}_{\mathbf{2}}$, and $\mathbf{p}$ is suitably distributed over a temporal period including $\mathbf{t}_{\mathbf{1}}$ and $\mathbf{t}_{\mathbf{2}}$. So, consider the example of my standing up. I initially exhibit the point feature of being bent and subsequently, the point feature of being straight. But I do so in virtue of possessing one and the same property in both the initial and final states of the change-namely, the distributional property of being initially bent and then straight.

Notice that the success of the distributional analysis of change depends on the irreducibility of the distributional properties. If x's point features of, say, being bent and being straight are to be explicated in virtue of $\mathbf{x}$ possessing one and the same property over time, being initially bent and then straight, then this distributional property ought not be analysable as an arrangement of these very point features.

Now our second example. Schaffer (2010a) advocates priority monism, the view that there is a single fundamental object, the world itself. The world has parts, but these parts are derivative. How explain basic heterogeneous entities? As Schaffer (2010a, p. 60 n. 39) notes, this issue of heterogeneity for the monist is analogous to

\footnotetext{
${ }^{8}$ On priority monism, Schaffer (2010a); discussed in Sider (2007, 2008), Morganti (2009), Trogdon (2009), Spencer (2010), Tahko and O’Conaill (2012), Kriegel (2012), Paul (2013), Tallant (2014), Effingham (2015), Schaffer (2016) and Brzozowski (2016).

9 Discussed by McDaniel (2009).
} 
the problem of intrinsic change-i.e., temporal heterogeneity-for enduring objects, discussed in the previous section. Schaffer prefers to explain heterogeneity by appeal to distributed properties. Schaffer (2010a, p. 60) writes:

For the monist, the general fact that the world is heterogeneous is due to the world's instantiating the determinable property of being heterogeneous. The specific way that the world is heterogeneous is due to the world's instantiating the determinate property of tracing such-and-such a curve through physical configuration space. Thus the one whole can be parturient.

Similar moves are offered by other theorists. Cornell $(2013,2016)$ defends the counter-intuitive position of existence monism, the view that there is only one entity, the world itself, which is mereologically simple-i.e., lacking proper parts.

Cornell appropriates the appeal to distributed properties so to provide an explanation of heterogeneity. And McDaniel (2009) considers the application of distributed properties to extended simples. Such objects are mereologically simple but nonetheless spatially extended. How might an extended simple enjoy qualitative variation? We cannot say that the extension has distinct parts which instantiate different properties. Ascribing to the object a distributed property is an initially promising line for the friends of extended simples to explain qualitative variation.

Notice that Parsons' strategy to argue for the irreducibility of distributed properties is not obviously available for existence monists, or friends of extended simples. Parsons, recall, draws on the possibility of gunk to establish irreducibility. But an extended simple lacks parts and so a fortiori is not gunky. Existence monists, similarly, cannot say that the singular world is gunky due to the world's mereological simplicity. There are options here. For example, one might hold that existence monism is merely contingently true. Under this modal qualification, existence monism is compatible with the claim that the world is possibly gunky. And friends of extended simples typically only claim that a mereologically simple yet extended object is possible. Alternatively, these theorists may simply stipulate that there are relevant irreducible distributed properties. For example, Cameron $(2008,2011)$ appeals to distributed properties so to provide truthmakers for past claims; in response, Corkum (2014) argues that presentists lack an attractive non-stipulative defense of such an approach. Green (2017) defends this strategy of stipulation.

\section{Objections to Distributionalism}

Let's call anyone who uses irreducible non-uniformly distributed properties in the manner of the previous section a distributionalist. I will next consider a few objections others have raised against distributionalism.

Our first objection. As we have seen, the friend of extended simples might explain qualitative heterogeneity by appeal to an irreducible, non-uniform distributional property. In discussion of this view, McDaniel (2009) objects that how an object is here and now is determined by how things are elsewhere. McDaniel (2009, p. 330) writes: 
if distributional properties are fundamental, how an object is here or now is metaphysically determined by how things are elsewhere. But should not the local intrinsic features of an object at a region be determined by the properties that are located at (and only at) that region? It is probably question-begging to use this brute intuition against the friend of distributional properties, and it is in this context a bit odd, since a non-local determination of some local matters of fact might be congenial to the friend of extended simples. Existence monists, for example, might wish to embrace the global determination of all local matters of fact.

There is something to McDaniel's objection that initially may appear to be worrying for distributionalism generally. The explanation of a thing being straight by appeal to a property of being initially bent and then straight seems to draw features of the thing at other times into the explanation. The objection is not that there is no local determination on the distributionalist's picture. How things are here and now is indeed determined by how things are everywhere-including here and now-in the presence of a specification of time and place. It is not that how things are here and now is left underdetermined by a property exemplified here and now (and is instead determined only by a property exemplified elsewhere). Nor is there a problem of overdetermination, that the exemplification of a property elsewhere as well as the exemplification of a property here both determine how things are here and now. For one thing, it is the same property there and then as here and now.

Rather, McDaniel's objection is that the local intrinsic features of an object at a region should be determined by properties located at and only at that region. I am not sure that I share McDaniel's intuition that there is something unattractive about non-local determination. But regardless, as McDaniel notes, the distributionalist ought to reject the view. For it is partly constitutive of distributionalism that local features are determined globally.

Other objections suggest that the distributionalist property exhibits unattractive features as an explanation of the point features-for example, that the distributionalist reverses the appropriate direction of explanation or that the distributional property provides an alleged explanation which fails to exhibit a formal feature required of explanations. For example, Sider (2007) raises an objection to the priority monist appealing to distributional properties so to explain qualitative heterogeneity among basic entities. Sider (2007, p. 3) writes:

Consider a world containing just a single computer screen with a $4 \times 4$ pixel resolution. Each pixel can be on or off. Since there are 16 pixels, and there are two states for each pixel, $2^{16}$ states are possible for the entire screen. The existence of this state-space is common ground between monists and pluralists. But only the pluralist can give a satisfying account of why the state-space has $2^{16}$ members. The pluralist can say: the state-space has $2^{16}$ members because (i) there are 16 pixels, each of which has two available fundamental states; (ii) the fundamental states of the system include only the states of the individual pixels; and (iii) the possibilities for the entire system are generated combinatorially from the entities in the system and the fundamental states those entities 
can inhabit. The monist can tell no such story. For the monist, the fundamental properties are the members of the state-space itself: the $2^{16}$ maximally specific properties of the entire screen. These properties are not generated combinatorially from more fundamental pixel-properties. Why, then, are there exactly $2^{16}$ of them?

Sider notes that there is an attractive explanation of the state-space in terms of the pixels, their states and certain combinatorial facts. Sider's complaint appears to be that there's available to the distributionalist no explanation of the state-space; their members are basic and inexplicable. But it is unclear to me why the fact that there is a $4 \times 4$ pixel grid, or two states for each pixel, ought to be more fundamental. The distributionalist can reverse-engineer the characterization of the screen as having a $4 \times 4$ grid of pixels, each with two possible states. Indeed, given her theoretic commitments, the priority monist must say that the existence and states of the pixels is not among the fundamental facts of this world. The distributionalist does not aim to answer Sider's question. Indeed, according to the distributionalist, there is no answer why there are $2^{16}$ states: this fact is fundamental and is used to explain why, as derivative facts, there is a $4 \times 4$ grid with each pixel having two states. ${ }^{10}$

These two objections might be viewed as variations on the objection that distributional facts fail to determine, or fail to adequately determine, the point feature facts. On this reading, each objection places some requirement on determination for determination to be explanatory-that the determination be local or exhibit some other desirable explanatory feature, such as a combinatorial explanation. The charge is that the distributional facts fail to determine the point features, or that they fail to satisfy some other requirement and so they do not determine the point features in a way that allows the distributional facts to explain the point feature facts. None of these charges would be compelling to the distributionalist. Yet the reader might share with me the feeling that there is some sense in which the distributional facts fail to explain the point features. The distributional facts are in some way at least partly otiose in the explanation of the point features. Although I have not shown that there is no restriction on determination that will capture this discomfort, I will next suggest a different tack.

\footnotetext{
10 Thanks to an anonymous reviewer, who suggests an alternative reading of Sider's objection: "the pluralist's theory is explanatorily preferable [to the monist's]: On the basis of just two possible states for each pixel and the fact that there is a $4 \times 4$ grid of pixels, the pluralist can explain the existence of all $2 \wedge 16$ possible states. But the monist must accept $2 \wedge 16$ possible states in order to explain the existence of the grid and each pixel's having two possible states. The monist's explanans seems much more complex, in part because it has to accept many more unexplained possibility facts, i.e. for each of the $2^{16}$ possible states, rather than just two possibility facts for each pixel." I agree that there may be this additional objection to monism-interestingly, by appeal to the cognitive value of simplicity, in addition to the objection from salience failure which I will go on to present. And I do not suggest that salience failure is the only cognitive shortcoming of distributionalism. It is less clear to me that one ought to read Sider as endorsing this objection from simplicity, or prefer this reading to the one presented in the paper, on which the objection is that the distributionalist facts fail to determine the point features.
} 


\section{Salience}

Let me take up a suggestion from Tahko and O'Conaill. Addressing the view that a colour property distributed over the surface of a ball can serve as the truthmaker for the claim that a given point on the ball's surface has a certain colour, Tahko and O'Conaill (2012, [12] n. 19) write:

It is correct that different judgements can be made true by the same state of affairs (e.g., 'The ball is red' and 'The ball is coloured'). However, the total condition of the ball is not appropriate to serve as the truth-maker, since it includes features which are irrelevant to either of the judgements under consideration. This objection to coarseness applies, only far more strongly, to any appeal to the cosmos as the truth-maker of either of these judgements.

There is something that feels right about this line of objection in its broad strokes. For example, it seems that the property of being polka-dotted red on white offers much more information than is needed for specifying the feature of one spatial point as, say, red. But the problem is not coarseness, as I see it. Coarse-grainedness objections tend to charge a proposed explanans with failure to determine the specific details of the explanandum. For example, the criticized proposal may be a genus that fails to specify the differentia needed to pick out a species; or a determinable property that fails to specify a more determinate feature. The situation with distributionalism is quite different. Although a distributional property appears to offer a surplus of information, it does not offer insufficiently detailed information. The distributional property does indeed determine, in the presence of a specification of time or place, the point features. And so the distributionalist is not vulnerable to a coarseness objection. Indeed, in this respect, Tahko and O'Conaill's objection is akin to the objections made by McDaniel and by Sider: all three are variants of the mistargeted objection that the distributional facts fail to adequately determine the point facts.

Rather, I want to take up Tahko and O'Conaill's suggestion that the shortcoming of certain distributionalist explanations is due to something like a failure of relevance. Some care is needed here. The term 'relevance' carries different meanings in different philosophical settings. But with the way I use 'relevance' and 'salience', distributional facts arguably fail to exhibit salience to, and not relevance for, explaining the point facts. (I do not suggest that Tahko and O'Conaill use 'relevance' in my way.) So let me discuss the distinction between relevance and salience.

It might be helpful by beginning with an example of the role given to relevance in the epistemology literature. The reader is likely familiar with Dretske's relevant alternatives theory of knowledge, on which knowledge requires ruling out relevant alternative possibilities. To know, when I visit the zoo, that I am looking at a zebra, I need to rule out the possibility that I am looking at an okapi, but I do not need to rule out the possibility that I am looking at a cleverly painted mule, since only the former possibility is typically relevant, given that zoos often have okapi but seldom if ever have painted mules. By contrast, to know that I am not looking at a cleverly painted mule, I must be able to rule out the possibility that I am looking at a cleverly 
painted mule, since this possibility is relevant to my knowing that I am not looking at a cleverly painted mule. In motivating just now the contrast between relevant and irrelevant alternatives, I gestured towards what sort of animal is typically found in zoos. But it is difficult to give general guidance as to when a possibility is relevant. Partly for this reason, epistemologists such as Stine (1976), Cohen (1988, 1999) and Greco (2004) have viewed the distinction between relevant and irrelevant alternatives to be mysterious, and have hoped to replace talk of relevance with a psychological distinction between what is and what is not salient to a speaker.

The psychological state of taking a certain feature or state of affairs to be salient is not simply attending to that feature or having that state of affairs in mind. To stay a moment longer with our epistemological example, I can attend to the possibility of there being painted mules at the zoo, without thereby taking that possibility to be salient to the question whether I know I am looking at a zebra, if I take that possibility to be sufficiently remote. The psychological state of viewing a state of affairs as salient to my knowledge is rather a judgment that that state of affairs plays a significant role in the warrant for holding my belief. I may rightly view the possibility of there being painted mules at the zoo as playing no such role, and my taking this possibility to be not salient is partly due to my holding this view. By contrast, the possibility that I am instead looking at an okapi is salient to my knowing that I am looking at a zebra in part because the presence of okapi in zoos is not unusual, and so my belief is warranted only if I can rule out this possibility. The salience of this possibility is partly constituted by my recognition of this justificatory role. ${ }^{11}$

The distinction between what is salient and what is not salient to interlocutors is already required to model ordinary discourse, independently of the special demands the linguistic act of explanation places on semantics. For example, as Stanley (2005, pp. 19-20) notes, salience can be used to fix the domain of restricted quantifiers. Suppose a speaker, looking into the fridge, utters 'There's no beer!' The restricted domain of the quantifier is determined by what domain the speaker has in mind. Similar appeals to the psychological states of the interlocutors determine the set of discourse referents resolving anaphora, as when you arrive at the party and say to me 'He's not here!' Sometimes these semantic features can be inferred from the linguistic context of an utterance, or by extralinguistic facts not involving the psychological states of the interlocutors. If the speaker is looking into the fridge while uttering 'There's no beer!', the intended domain restriction is clear. Or if your utterance at the party occurs after I ask you if Freddy is here, the referent for your use of 'he' is transparent. But sometimes,

\footnotetext{
11 For the observation that such salience is not mere attention, see Hawthorne (2004, p. 64), who characterizes a salience constraint on knowledge in terms of taking certain possibilities of error seriously. One might wonder why recognition is important here. The possibility of okapi would be salient even if the observer didn't recognize either the possibility or its justificatory role. Thanks to an anonymous reviewer for the objection. In response, notice that salience, unlike relevance, is a psychological state partly constituted by attention and, for the reasons rehearsed above, partly constituted by recognition of a certain role. In the okapi case, the possibility of okapi might be relevant to justification but, if the ascriber does not attend to the possibility and recognize its role in justification, the possibility is not salient.
} 
the context in which the utterance is made, and the previous statements in the discourse in which the utterance occurs, are insufficient to fix restricted domains or resolve anaphora. In such cases, features may only be determined by the psychological states of the interlocutors. The speaker of the first utterance has a domain in mind, the objects in the fridge; and moreover she views this set as the domain over which the quantifier in the utterance ranges. Similarly, the speaker of the second utterance has an individual in mind as the person being talked about. In these cases, a set of objects is salient to the speaker and it is this psychological state, the state of attending to the set with the intention of delimiting a domain or providing a set of discourse referents, that fixes the restricted domain of the quantifier or resolves anaphora. ${ }^{12}$

So rather than introducing a new distinction between what is relevant and what is irrelevant, and facing the challenge of providing a principled general basis for such a distinction, let us instead draw on the distinction between what is salient and what is not salient to a speaker, a distinction that is reasonably familiar and one which we already need for semantics. With this in mind, I return to our discussion of explanation.

One area where the value of salience for explanations is discussed is in the literature on causal explanation. So let me draw on this analogy between metaphysical explanation and causation. There are differences between metaphysical explanation and causation-metaphysical explanation involves a synchronic relation between facts; causation arguably involves a diachronic relation between eventsbut analogies between metaphysical explanation and causation can be fruitful. In the causation literature, salience is sometimes drawn on in an account of why certain purported causal stories are not explanatory. To give an example, consider the claim that a sugar cube dissolves in a certain liquid because the liquid is holy water. A purported explanation such as this claim typically fails salience requirements. In most situations where one aims to explain the dissolution of the sugar cube, the interlocutors would neither attend to the water's ecclesiastical status, nor take this status as a prominent component of the causal role of the water.

But the notion plays a role in a wide variety of explanations, including ascriptions of praise and blame, and mathematical proofs. ${ }^{13}$ I will give just one further example. Feinberg (1970) views salience as playing a key role in moral praise and blame. To blame or praise is to ascribe causal responsibility-this requires not to relate the full causal story of how some action takes place, but to identify a particularly important part of the causal story. Feinberg argues that it is the habitual character of the agent which is what is salient for their moral blameworthiness. Feinberg's account is applicable to other kinds of praise and blame-for example, athletic achievements. We praise the athleticism of the outfielder who makes a

\footnotetext{
12 One might respond that salience plays only an epistemic role-what (constitutively) determines content is the speaker's intention. Thanks to an anonymous reviewer for the objection. In response, notice that what objects are salient to the interlocutors partly contributes to the intentions and so partly determines the content of what is said.

${ }^{13}$ Lange (2014) distinguishes explanatory from non-explanatory mathematical proofs by appeal to salience.
} 
spectacular running catch, but not the equally capable outfielder who trips and has the ball fall in his glove by chance. Feinberg's discussion suggests that this is because it is the athletic ability of the first outfielder which is salient to our ascription of praise. By contrast, it is the luck of the second outfielder which is salient to our withholding praise.

Now consider the case of distributional properties. The reason that the irreducible, non-uniform distributional properties arguably make poor explanations for the points features is that the distributional property appears to exhibit attenuated salience. For example, consider our toy example of the irreducible property of being polka-dotted red on white employed as explanans in an explanation of a given red surface point. While there is an aspect of the property of being polkadotted red on white which is salient for explaining what this surface point is the colour that it is-red, say-there are other aspects of the property which are not salient. On the whole, the property scores low for salience because its dominant, distinctive or prominent feature is not redness but the pair of colours (white, red) and the arrangement (polka-dotted). These features are idle in the explanation of the redness of a given red surface point. And in a purported explanation of the local redness by appeal to the surface being polka-dotted red on white, the interlocutors would not attend to the reference to redness in the explanans as having special significance to the explanation. Similarly, facts about global properties distributed over an extension give to presentists truthmakers for past claims; give to priority monists an explanation of basic heterogeneous entities; and give to friends of extended simples an explanation of how an extended simple can enjoy qualitative variation-but all these explanations arguably exhibit attenuated salience.

The objection that a distributed property lacks salience and so is ill-suited to explain point features is distinct from any of the objections considered previously. For example, the charge of salience-failure is not the complaint that the distributed property is under-determined or unattractively determined, that the distributed property is insufficiently fine-grained, or that the distributed property fails to conform to requirements of locality. ${ }^{14}$

\footnotetext{
14 Thanks to anonymous reviewers who offered alternatives or alterations to distributionalism, to meet the objection against the position raised in the paper. For example, one reviewer questions whether there are views that are not subject to a salience failure objection - such as an explanation that appeals to a determinable property (being polka-dotted red on some colour or other) or an explanation that appeals to Schaffer's contrastivist construal of grounding (being polka-dotted red, as opposed to some other colour, on white). Although this may not have been the intentions of the reviewer, note that determinables exhibit features similar to focus sensitive characterizations (being polka-dotted [red $]_{\mathrm{F}}$ on white). However, modelling salience on analogy with determinable features has the potential to mislead, since distributional facts are fully determinate, and determinable features typically would not be taken to ground determinate features; of course, I do not claim that the reviewer is misled on these points. Similarly, contrastivist explanations induce features similar to focus sensitive characterizations. But questions of salience arise for contrastivist approaches: I doubt that the surface being polka-dotted red, as opposed to some other colour, on white, provides a more salient explanation of this point being red than the surface being polka-dotted red on white; but even if one holds that the former is more salient than the latter, it is an open question whether either explanation exhibits sufficient salience.
} 


\section{Salience and An Analogy With Focus Sensitivity}

How ought we to think of salience and is the distributionalist vulnerable to the charge of salience-failure? Here's one way to develop an account of salience. Let's continue the analogy between metaphysical explanation and causation. In the causation literature, many authors discuss causal differences. Lewis (1986) gives the following example. John's saying hello must differ from John's saying hello loudly, since only the former causes Fred to respond, and only the latter is caused by John's tension. Some respond by arguing that causal differences such as in the John case adduce explanatory differences only, not differences in the individuation of causal relata. One way of cashing out this thought is by distinguishing causation and explanation. For example, Davidson (1980) holds that while causation is an extensional relation that holds between coarse events, explanation is an intensional relation that holds between the coarse events under a description. Others, such as Anscombe (1975), take a causal ascription to be an intensional context. So John's saying hello and John's saying hello loudly are the same event but the one cannot necessarily be substituted salva veritate within a causal ascription. These responses allow the causal relata to be individuated more coarsely, while allowing that either causal explanations or causal ascriptions are finer grained.

The distributionalist might then retort to the charge of salience-failure as follows. What distributed property is instantiated is a coarse-grained fact which determines the facts about what point features are instantiated. It is for example the instantiation of an irreducible property of being polka-dotted red on white that determines that this point is red. But this fact plays a role in the explanation of a red point feature only under an emphasis or description. The fact that the whole surface is polkadotted red on white is the same fact as the fact that the whole surface is polka-dotted red on white, but it is that fact only under the former description that explains the fact that this point on the surface is red.

How might we cash out this idea? Here's a suggestion: consider linguistic theories of focus. Why turn to linguistics, when we've been doing metaphysics? We express metaphysical explanations with a fragment of a natural language such as English. The empirical study of the linguistic features of that fragment offers defeasible but prima facie evidence for developing a theory of metaphysical explanations. And even though the expression of a metaphysical explanation generally does not employ explicit focus markings, we will see that a theory of focus sensitivity provides structure analogous to salience. And so a detour into this linguistic theory will prove to be fruitful for our purposes.

Some expressions exhibit focus sensitivity. Truth conditions for sentences containing these expressions vary according to what other part of the sentence is emphasized. Linguistic theories of focus study a wide range of expressions-exclusives such as 'only', scalar additives such as 'even', non-scalar additives such as 'also', quantificational adverb such as 'always', quantificational determiners such as 'many', particularizers such as 'for example', and intensives such as 'really', among others. Consider an example with an exclusive, adapting an example given in Beaver 
and Clark (2008, p. 53). I'll follow the convention of indicating a focused constituent with a subscripted 'F'.

(1) Kim only serves Sandy [Johnnie Walker $]_{F}$.

(2) Kim only serves $[\text { Sandy }]_{F}$ Johnnie Walker.

The difference in emphasis renders (1) appropriate for answering the question, 'What does Kim serve Sandy?' and (2) appropriate for answering the question, 'To whom does Kim serve Johnnie Walker?' Call the congruent question the Current Question. Such differences are partly pragmatic, since they rely on features such as intonation and contextual considerations that indicate the Current Question. But although pragmatically specified, the features that distinguish (1) and (2) are not cancelable implicatures but have robust effect on the truth conditions. For example, in the situation where Kim serves both Sandy and Matilda Johnnie Walker and no other drink, (1) is true and (2) is false.

Exclusives such as 'only' are attached to a prejacent proposition. For example, the prejacent for both (1) and (2) is.

(3) Kim serves Sandy Johnnie Walker.

Exclusives are scalar expressions. They are associated with an ordering of propositions from weaker to stronger. For example, (1) is associated with an ordering such as $<$ Kim serves Sandy, Matilda and Vivian Johnnie Walker, Kim serves Sandy and Matilda Johnnie Walker, Kim serves Sandy Johnnie Walker $>$. Exclusives comment on an overly strong expectation regarding the answer to the Current Question. The effect on the flow of information is to say that the strongest true answer is the prejacent.

Other expressions which exhibit focus sensitivity are non-scalar. For example, consider an additive such as 'too'. Beaver and Clark (2008, p. 72) adapt an example from Kripke (2009):

(4) Tonight $[\mathrm{Sam}]_{\mathrm{F}}$ is having dinner in New York, too.

(5) Tonight Sam is having dinner in $[\mathrm{New} \text { York }]_{\mathrm{F}}$, too.

Beaver and Clark (2008, p. 72) view (4.4) as congruent to the question Who is having dinner tonight in New York? (4) is associated with a set of propositions of the form $x$ is having dinner tonight in New York, with the variable domain ranging over other diners in New York. The additive conveys that this question has already been partly answered, with someone other than Sam also having dinner in New York, and so it is known to the interlocutors that one of these propositions is true. Similarly, (5) is congruent to the question Where is Sam having dinner tonight? and is associated with a set of propositions of the form Sam is having dinner tonight in $x$, with the variable domain ranging over places other than New York where Sam eats, and it is implied that at least one of these propositions is true.

Explanations can also be focus sensitive. Consider.

(6) This point is red because the surface is polka-dotted $[\mathrm{red}]_{\mathrm{F}}$ on white.

(7) This point is red because the surface is polka-dotted red on [white $]_{F}$. 
Notice that here too focal differences have semantic effects. In the situation of our toy example, arguably, (6) is true and (7) is false. The analysis of focus sensitivity sketched above suggests that the effect of the focus is to define distinct Current Questions for the two because-clauses: for example, (6) might be appropriate for answering the question What colour are the polka-dots? and (7) might answer the question What colour is the background to the polka-dots? Associated with each Current Question is a class of possible answers. For example, (6) is associated with a set of propositions of the form the surface is polka-dotted $x$ on white, with various colours in the domain of substitution for the variable. Explanatory expressions such as 'because' are non-scalar: like additives such as 'too' and unlike exclusives such as 'only', the propositions associated with (6) are unordered.

The distributed property, being polka-dotted red on white, has explanatory force in the presence of the factors that determine where in the property's configural path the red point lies. It is because the point occurs in the foreground of a polka-dotted array, as opposed to occurring in the background, that a range of possible foreground colours is salient; and it is because the foreground colour is red, as opposed to one of these other colours, that the point is red. The focus marking in (6) implies that it is understood among interlocutors that this point is within the foreground of a polka-dotted array. And so the embedded clause in (6) is explanatory of the relevant point feature. The focus marking in (7), by contrast, implies that it is understood among interlocutors that this point is within the background of a polka-dotted array; and so the embedded clause fails to be explanatory of the point feature.

The distributionalist who accepts a salience requirement on explanation might appeal to focus sensitivity along these lines, so to show that distributed properties can be explanatory. Nonetheless, perhaps some discomfort with distributed properties as an explanans for the point features lingers in the reader. Can we account for this discomfort? Salience admits of degree. And in this case there is a reasonably precise way of articulating a scale according to which we can distinguish the robustly salient from the weakly salient. As a rough quantitative basis for a scale of salience, one might consider what alternative focus markings must be ruled out pragmatically. For our example, we must rule out alternative readings such as.

(7) This point is red because the surface is polka-dotted red on [white $]_{\mathrm{F}}$.

(8) This point is red because the surface is [polka-dotted $]_{F}$ red on white.

A successful explanation that is invariant under differences of emphasis, and does not exhibit any focus sensitivity whatsoever, would score high on this salience scale. For example, in the case where a surface is uniformly one colour, the following explanation is highly salient.

(9) This point is red because the surface is uniformly red.

Different focus markings do not change the truth value of (9). On the other hand, an explanation where an alternative reading must be ruled out for the explanation to be successful exhibits less salience. On this scale, (6) exhibits less salience in its situation than (9) exhibits in its situation. 
Moving beyond toy examples of explanans such as being polka-dotted red on white is not straightforward. A global property distributed over the extension of an extended simple, for example, typically would not be expressed by a term with sufficient complexity to allow for differences of stress to induce semantic differences similar to those induced by 'being polka-dotted [red $]_{\mathrm{F}}$ on white' and 'being polkadotted red on [white $]_{\mathrm{F}}$ '. But analogous semantic differences may be induced by the context of the explanation. In the context of explaining a local feature, the interlocutors take some aspect of the distributed property seriously as playing a significant role in the explanation. That is to say, they take some aspect of the distributional facts to be more salient, and other aspects less salient.

So goes a sketch of one approach to salience. Let me make a few disclaimers. I do not claim that this smattering of focus theory will provide a general theory of salience. I also have offered a guideline for differentiating degrees of salience within this approach. The guideline considers alternative focus markings with robust semantic effect. But I do not claim that such considerations are the only, or the best, way of differentiating degrees of salience. Instead, I offer these sketches as an approach to salience that tracks certain intuitions I have in our target cases. Finally, it may be worth emphasizing that the discussion of focus sensitivity in this section is not intended to suggest a solution for the distributionalist, but instead to suggest a semantic model for characterizing salience success and failure. My claim is that differences in linguistic stress induce semantic differences relevantly similar to the semantic differences induced by differences in salience. This observation is compatible with there being disagreements over whether a purported explanation has sufficient salience. Distributionalists might find that 'That is red because it is polkadotted [red $]_{\mathrm{F}}$ on white' exhibits sufficient salience; others might disagree; the discussion in this section aims to bring out a clear way of articulating the disagreement. ${ }^{15}$

\footnotetext{
15 Thanks to an anonymous reviewer who raises concerns with the discussion of focus sensitivity in this section. They write that "the author claims that certain 'because'-claims that the distributionalist is committed to appear problematic due to their low salience, but with the correct focus-markings, they can be given an acceptable reading." The reviewer raises several worries arising from this claim. For example, although the focus-marked 'That is red because it is polka-dotted [red] $]_{\mathrm{F}}$ on white' is acceptable, the reviewer finds the non-focus-marked 'That is red because it is polka-dotted red on white' to be also acceptable. The reviewer finds some of the sentences discussed to be not clearly cases of explanatory uses of 'because' since they may be epistemic cases. Finally, the reviewer notes that the claim overgenerates, since it counts 'This is red because this is round and [scarlet $]_{\mathrm{F}}$ ' as acceptable but conjunctive facts make for poor grounds. In response, I welcome the opportunity to clarify and emphasize the intentions of this section of the paper, which is not to show that there are acceptable readings of distributionalist explanations. Personally, I find such explanations to exhibit salience failure. Competent language users can disagree whether the non-focused-marked sentence 'That is red because it is polka-dotted red on white' is acceptable, provided there is not robust disagreement that the sentence exhibits less salience than its focus-marked counterpart. The observation is also compatible with purported explanations exhibiting different degrees of salience yet failing as explanations for other reasons - for example that the sentence employs an epistemic sense of 'because' or that the purported explanation flouts other requirements placed on grounds, such as prohibitions against conjunctive facts serving as grounds.
} 


\section{Conclusions}

How might a distributionalist respond? Those who have appealed to such properties, so to give to monists or friends of extended simples an account of qualitative heterogeneity, or to give to presentists a response to the truthmaker objection, or to provide an analysis of change, might well reject altogether the requirement of salience for metaphysical explanation. Indeed, they might take the above considerations to show only that anyone's discomfort with distributed properties is flowing from the cognitive demands of explanation. We need to draw attention to certain features of the fundamental facts so to engender understanding of how they ground other facts. But (the response might continue) metaphysical explanation is simply a determination relation that imposes a partial ordering on the ontology of facts. We ought to distill cognitive considerations from an account of objective ontological structure. In this way, distributionalists might use the above discussion so to provide an error theory of their opponents' mistake.

The paper is directed towards those who, like me, feel discomfort with distributed properties as the explanans for their associated point features. I have suggested that this discomfort is not due to the distributed property failing to adequately determine the point features. And I have offered attenuated salience as an analysis of the discomfort. If you feel discomfort, and you agree with the analysis, then you have a reason to view salience as a value for assessing metaphysical explanations no less than other kinds of explanations.

To note that a distributed property exhibits attenuated salience is not to say that the property has insufficient salience to adequately explain the associated point features. Although we have a way of specifying a scale so to assess degree of salience, there is no easy line of demarcation between the sufficiently salient and the nonexplanatory. The assessment whether distributed properties offer sufficient salience to be explanatory is a decision requiring consideration of the degree of salience relative to other costs and benefits of the proposal. These considerations may well conflict and so an assessment requires careful weighing of the value of salience against these other values. That is to say, the assessment requires not mere decision but judgment. ${ }^{16}$

Let's step back just a little. Recall that Raven raises a challenge for those 'separatists' who would distinguish metaphysical explanations from the worldly facts which back such explanations. Such separation would allow for facts about the instantiation of distributed properties to obtain independently of our interests, purposes and background beliefs, while viewing the employment of such facts in metaphysical explanations as sensitive to our epistemic situation. Opposed to separatists are the

\footnotetext{
16 As Feinberg (1970, p. 141) notes in another context. I do not claim that these observations could vindicate every variant of distributionalism. Specific uses of distributional properties in metaphysical explanations face specific challenges. For example, Sider (2007) argues that priority monism is incompatible with our best account of intrinsic properties. For discussion, see Trogdon $(2009,2010)$ and Skiles (2009). And Tallant and Ingram (2012a, b) and Corkum (2014) argue that there are reasons specific to presentism why presentists should not use distributional properties as truthmakers for past claims; for discussion see Cameron (2013) and Green (2017).
} 
unionists, who hold that mere citation of the worldly facts provides metaphysical explanations. The citation of facts is minimally evaluable by cognitive values and so, if citation is explanation, then such explanations are relatively insensitive to our epistemic situation. The challenge for separatists, as Raven characterizes it, is to show that grounds do not generally provide any kind of explanation. But we can concede to unionists that mere citation may provide a minimal explanation. The question is not whether an explanation is provided but whether the provided explanation is satisfactory. I've considered a case where facts about the instantiation of distributed properties are called to play the role of explanans in the explanation of facts about the corresponding point features. The distributional facts determine the point facts. But suppose you share my discomfort with distributional facts as explanations of the point facts. Then you have a reason to reject the grounding facts in this case as providing a satisfactory metaphysical explanation. And suppose further that you agree with my analysis of this discomfort in terms of attenuated salience. Then you have reason to hold that, although a purported explanans determines its corresponding explananda, it can fail to provide a good metaphysical explanation, if it lacks sufficient salience.

Okay, but should we care? One might after all agree that distributional facts are insufficiently salient to the point facts, so that the explanations canvassed in $\S 3$ fail as explanations, but view this explanatory failure as being of little concern to the metaphysician. Here is a picture of metaphysical inquiry that might support this view. The primary goal of metaphysics is to identify what grounds what. ${ }^{17}$ Once we have identified the grounding facts, and the facts about how these grounds determine the determine the derivative facts, we have achieved our goal. The conveyance of these facts, and thereby the explanation of the derivative facts by means of the grounding facts, is of secondary concern. And tracking and accommodating our own cognitive difficulties in appreciating what grounds what, lies outside the purview of metaphysical inquiry per se.

Apply this picture to distributionalism. Notice that a distributionalist might be either a separatist or an unionist. A distributionalist who is also a separatist might concede that, although the distributional facts determine the local facts, distributional facts might nonetheless provide a poor explanation of local facts. But a theorist who is both a distributionalist and an unionist would reject the requirement of sufficient salience for adequate explanations, on the grounds that metaphysical explanations are objective and insensitive to cognitive values. Such a theorist would be unmoved by the considerations of this paper. Indeed, they might well view these considerations as providing a defensive manoeuvre. If you find the global distributional facts to be insufficiently salient to local facts, you are (the defense goes)

\footnotetext{
17 For example, this appears to be the view of Schaffer (2009) and Sider (2011). For criticism of some aspects of this picture, see for example Barnes (2017) and Mikkola (2017). Sider (2017) and Schaffer (2017) respond in part by clarifying: the identification of what grounds what, plays a central role in metaphysics but is not the sole goal of metaphysical inquiry.
} 
mistaking the limitations of your cognition of the explanation for shortcomings in the explanation itself. $^{18}$

I do not know how to argue against this picture of metaphysics. But let me close by sketching a rival. The aim of metaphysical inquiry is not merely to identify what grounds what, but to use such facts with the goal of explaining the derivative facts. Metaphysics aims at truth, of course; but metaphysics also aims at understanding. On this picture, we ought to take seriously, as part of the metaphysical endeavour, the cognitive evaluation of metaphysical explanations.

Acknowledgements Thanks to the auditors at papers delivered to the Creighton Club New York Philosophical Association Annual Conference, Syracuse; the Annual Meeting of the Society for Exact Philosophy; the 3rd Epistemology of Metaphysics Workshop, Helsinki; the Canadian Philosophical Association Annual Congress, Montreal; and the University of Victoria. Thanks especially to Kris McDaniel, Howard Nye, and Tuomas Tahko. And thanks most especially for written comments to Paul Audi, Jayson Payton, and Mike Raven. I gratefully acknowledge a Vice President Research Social Sciences and Humanities Research Council of Canada Grant Assist Bridge Funding Award and the Social Sciences and Humanities Research Council of Canada Insight Development Grant \#430-2020-00713 for financial support.

\section{References}

Anscombe, G. E. M. (1975). Causality and Determination. In E. Sosa (Ed.), Causation and Conditionals (pp. 63-81). Oxford University Press.

Audi, P. (2012). Grounding: Toward a theory of the In-Virtue-of relation. Journal of Philosophy, 109, $685-711$.

Barnes, E. (2017). Realism and social structure. Philosophical Studies, 174, 2417-2433.

Beaver, D., \& Clark, B. (2008). Sense and Sensitivity: How Focus Determines Meaning. Oxford: Wiley-Blackwell.

Bliss, R., \& Trogdon, K. (2016). Metaphysical Grounding. In E. N. Zalta (Ed.), The Stanford Encyclopedia of Philosophy (Winter 2016 Edition). https://plato.stanford.edu/archives/win2016/entries/groun ding/.

Brzozowski, J. (2016). Monism and Gunk. In M. Jago (Ed.), Reality Making. Oxford: Oxford University Press.

Cameron, R. (2008). Comments on Merricks' truth and ontology. Philosophical Books, 49, $292-301$.

Cameron, R. (2011). Truthmaking for Presentists. In D. Zimmerman (Ed.), Oxford Studies in Metaphysics (Vol. 6). Oxford: Oxford University Press.

Cameron, R. (2013). Changing Truthmakers: Reply to Tallant and Ingram. In D. Zimmerman (Ed.), Oxford Studies in Metaphysics (Vol. 8). Oxford: Oxford University Press.

Caplan, B., \& Sanson, D. (2011). Presentism and truthmaking. Philosophy Compass, 6, 196-208.

Cohen, S. (1988). How to be a Fallibilist. Philosophical Perspectives, 2, 91-123.

Cohen, S. (1999). Contextualism, skepticism, and the structure of reasons. Philosophical Perspectives, $13,57-89$.

Corkum, P. (2014). Presentism, truthmakers and distributional properties. Synthese, 191, 3427-3446.

Cornell, D. (2013). Monism and statespace: A reply to sider. Analysis, 73, 230-236.

Cornell, D. (2016). Taking monism seriously. Philosophical Studies, 173, 2397-2415.

18 It might be helpful to the reader to clarify the dialectic of the paper. Speaking for myself, I view this variation of distributionalism, and its attendant defensive manoeuvre, as mistaken, for the reason I sketch in the next paragraph. But other than this mere sketch, I cannot here develop a criticism of unionism further. I believe that the considerations raised in this paper put pressure on the distributionalist who is also a separatist, and they make further discussion of the unionist-separatist distinction urgent. Thanks to an anonymous reviewer for pressing me to be clearer on these points. 
Correia, F., \& Schnieder, B. (Ed.). (2012). Grounding: An Opinionated Introduction. In Metaphysical Grounding: Understanding the Structure of Reality. Cambridge: Cambridge University Press.

Dasgupta, S. (2014). On the plurality of grounds. Philosophers' Imprint, 14, 1-28.

Davidson, D. (1980). Causal Relations. orig. 1967. In Essays on Actions and Events (pp. 149-162). Oxford: Clarendon Press.

Davidson, M. (2013). Presentism and Grounding Past Truths. In R. Ciuni, K. Miller, \& G. Torrengo, (Eds.), New Papers on the Present-Focus on Presentism. Munich: Philosophia Verlag.

Douglas, H. (2009). Science, Policy, and the Value-Free Ideal. University of Pittsburgh Press.

Effingham, N. (2013). Harmoniously investigating concrete substances. Thought, 2, 190-195.

Effingham, N. (2015). Properties are Potatoes: An Essay on Ontological Parsimony. In C. Daly (Ed.), The Palgrave Handbook of Philosophical Methods. London: Palgrave Macmillan.

Feinberg, J. (1970). Action and Responsibility. In Doing and Deserving. Princeton: Princeton University Press.

Fine, K. (2001). The Question of Realism. Philosophers'. Imprint, 1, 1-30.

Greco, J. (2004). Knowledge as Credit for True Belief. In M. DePaul \& L. Zagzebski (Eds.), Intellectual Virtue: Perspectives from Ethics and Epistemology. Oxford: Oxford University Press.

Green, M. (2017). Presentism, Distributional Properties, and Fundamentality. Aporia, 16, 1-8.

Hawthorne, J. (2004). Knowledge and Lotteries. Oxford University Press.

Hempel, C. (1965). Aspects of Scientific Explanation and Other Essays in the Philosophy of Science. Free Press.

Koslicki, K. (2012). Varieties of Ontological Dependence. In F. Correia \& B. Schnieder (Eds.), Metaphysical Grounding: Understanding the Structure of Reality. Cambridge: Cambridge University Press.

Kriegel, U. (2012). Kantian monism. Philosophical Perspectives, 41, 23-56.

Kripke, S. (2009). Presupposition and Anaphora: Remarks on the Formulation of the Projection Problem. Linguistic Inquiry, 40, 367-386.

Lange, M. (2014). Aspects of mathematical explanation: symmetry, unity and salience. Philosophical Review, 123, 485-531.

Lewis, D. (1986). Events. Philosophical Papers 2 (pp. 241-269). Oxford University Press.

Lewis, D. (1991). Parts of Classes. Basil Blackwell.

Litland, J. (2013). On some counterexamples to the transitivity of grounding. Essays in Philosophy, 14, $19-32$.

McDaniel, K. (2009). Extended simples and qualitative heterogeneity. Philosophical Quarterly, 59, 325-331.

Mikkola, M. (2017). Non-ideal metaphysics: On the apparent antagonism between feminist and mainstream metaphysics. Philosophical Studies, 174, 2435-2448.

Morganti, M. (2009). Ontological priority fundamentality and Monism. Dialectica, 63, 271-288.

Parsons, J. (2000). Must a four-dimensionalist believe in temporal parts? Monist, 83, 399-418.

Parsons, J. (2004). Distributional Properties. In F. Jackson \& G. Priest (Eds.), Lewisian Themes. Oxford: Oxford University Press.

Paul, L. A. (2013). Categorical priority and categorical collapse. Aristotelian Society Supplementary Volume, 87, 89-113.

Raven, M. (2012). In defence of ground. Australasian Journal of Philosophy, 90, 687-701.

Raven, M. (2015). Ground. Philosophy Compass, 10, 322-333.

Rosen, G. (2010). Metaphysical Dependence: Grounding and Reduction. In B. Hale \& A. Hoffmann (Eds.), Modality: Metaphysics, Logic, and Epistemology. Oxford: Oxford University Press.

Ruben, D. (1990). Explaining Explanation. Routledge.

Schaffer, J. (2007). From nihilism to Monism. Australasian Journal of Philosophy, 85, 175-191.

Schaffer, J. (2009). On What Grounds What. In D. Chalmers, D. Manley, \& R. Wasserman (Eds.), Metametaphysics: New essays on the foundations of ontology (pp. 347-383). Oxford University Press.

Schaffer, J. (2010a). Monism: Priority of the whole. Philosophical Review, 119, 31-76.

Schaffer, J. (2010b). The least discerning and most promiscuous truthmaker. Philosophical Quarterly, 60, $307-324$.

Schaffer, J. (2012). Grounding, Transitivity, and Contrastivity. In F. Correia \& B. Schnieder, (Eds.), Metaphysical Grounding: Understanding the Structure of Reality. Cambridge: Cambridge University Press.

Schaffer, J. (2016). Monism. In E. N. Zalta (Ed.), The Stanford Encyclopedia of Philosophy (Winter 2016 Edition). https://plato.stanford.edu/archives/win2016/entries/monism/. 
Schaffer, J. (2017). Social construction as grounding; or: Fundamentality for feminists, a reply to Barnes and Mikkola. Philosophical Studies, 174, 2449-2465.

Sider, T. (2007). Against Monism. Analysis, 67, 1-7.

Sider, T. (2008). Monism and Statespace Structure. In R. Le Poidevin (Ed.), Being: Developments in Contemporary Metaphysics (pp. 129-50). Cambridge: Cambridge University Press.

Sider, T. (2011). Writing the Book of the World. Oxford University Press.

Sider, T. (2017). Substantivity in feminist metaphysics. Philosophical Studies, 174, 2467-2478.

Skiles, A. (2009). Trogdon on Monism and intrinsicality. Australasian Journal of Philosophy, 87, $149-154$.

Spencer, J. (2010). A tale of two simples. Philosophical Studies., 148, 167-181.

Skow, B. (2016). Reasons Why. Oxford University Press.

Stine, G. (1976). Skepticism, relevant alternatives and deductive closure. Philosophical Studies, 29, 249-261.

Stanley, J. (2005). Knoweldge and Practical Interests. Oxford University Press.

Strevens, M. (2008). Depth: An Account of Scientific Explanation. Harvard University Press.

Tahko, T., \& O'Conaill, D. (2012). On the Common Sense Argument for Monism. In P. Goff (Ed.), Spinoza on Monism, Philosophers in Depth series (pp. 149-166). New York: Palgrave Macmillan.

Tallant, J. (2014). Against mereological nihilism. Synthese, 191, 1511-1527. https://doi.org/10.1007/ s11229-013-0343-8.

Tallant, J., \& Ingram, D. (2012a). Time for Distribution? Analysis, 72, 264-270.

Tallant, J., \& Ingram, D. (2012b). Presentism and distributional properties. Oxford Studies in Metaphysics, 7, 305-314.

Tallant, D., \& Ingram, D. (2015). Nefarious presentism. Philosophical Quarterly, 65, 355-371.

Trogdon, K. (2009). Monism and intrinsicality. Australasian Journal of Philosophy, 87, 127-148.

Trogdon, K. (2010). Intrinsicality for monists (and Pluralists). Australasian Journal of Philosophy, 88, $555-558$.

Trogdon, K. (2013). An Introduction to Grounding. In M. Hoeltje, B. Schnieder \& A. Steinberg (Eds.), Varieties of Dependence: Ontological Dependence, Grounding, Supervenience, Response-Dependence. Munich: Philosophia Verlag. 